\title{
Body Composition, Muscle Strength Deficits and Mobility Limitations in Adult Survivors of Childhood Acute Lymphoblastic Leukemia
}

\author{
Kirsten K. Ness, PhD, $\mathrm{PT}^{1}{ }^{1}$ K. Scott Baker, MD, $\mathrm{MS}^{2}{ }^{2}$ Donald R. Dengel, $\mathrm{PhD},{ }^{3}$ Nancy Youngren, $\mathrm{RN},{ }^{2}$ \\ Shalamar Sibley, MD, ${ }^{4}$ Ann C. Mertens, PhD, ${ }^{1}$ and James G. Gurney, $\mathrm{PhD}^{5}$
}

\begin{abstract}
Background. Chronicity of muscle weakness from cancer and its treatment may be problematic, particularly in those treated for cancer during childhood. We compared body composition, muscle strength, and mobility between 75 adult survivors of childhood acute lymphoblastic leukemia (ALL) and expected values based on population normative data. Methods. Subjects were young adults treated for childhood ALL between 1970 and 1986, selected randomly from participants in an ongoing study of cancer survivors. DeXA scans were performed to evaluate body composition, and myometry used to measure strength. Mobility was evaluated with the Timed Up and Go (TUG) and 2-min walk (TMW). One sample $t$-tests compared ALL survivors to population norms. Results. Males had $4.5 \%$ and females had $2.3 \%$ more body fat than expected (expected
\end{abstract}

males $21.5 \%$, females $36.0 \%$ ). Males were 76.7 Newtons and females were 58.6 Newtons weaker in quadriceps strength than expected (expected males $569.87 \mathrm{~N}$, females $464.67 \mathrm{~N}$ ). Males walked $100.88 \mathrm{~m}$ and females walked $85.38 \mathrm{~m}$ less on the TMW (expected values: males $304.23 \mathrm{~m}$, females $276.26 \mathrm{~m}$ ), and took longer to complete the TUG (males 5.82 vs. $2.84 \mathrm{sec}$, females 5.88 vs. $3.00 \mathrm{sec}$ ) than expected. Treatment with cranial radiation and current growth hormone $(\mathrm{GH})$ deficiency were associated with lower body weakness among females. Conclusions. Young adult survivors of childhood ALL have strength and mobility deficits. Decreased strength may reduce ability to participate in physical activity, perpetuating fitness deficits in survivors of childhood ALL. Pediatr Blood Cancer 2007;49:975-981. ㄷ 2006 Wiley-Liss, Inc.

Key words: body composition; functional mobility; growth hormone deficiency; leukemia; muscle strength; radiation

\section{INTRODUCTION}

Muscle atrophy is associated with acute disease states, including malignancies $[1,2]$. In animal models, loss of muscular mass can occur from protein degradation in response to physiologic triggers from the tumor [3], lack of adequate nutritional intake, chemotherapy or radiation-induced toxicities [4], and prolonged inactivity, including bed rest. For children and adolescents who survive posttreatment, muscle catabolism can impact performance from muscle weakness and rapid fatigue long after treatment ends [5]. Losses in muscle strength and mass impact physical function and interfere with the ability to perform physical tasks necessary for everyday life $[6,7]$. The chronicity of muscle weakness in long-term cancer survivors is not well documented and may be problematic, particularly in those treated during childhood. Early loss of muscle mass during periods of rapid physical development may deplete protein stores such that full recovery is unlikely. Muscle weakness and associated frailty may result in a lifetime of sub-optimal physical ability and associated ill health [5-7].

A recent analysis from the Childhood Cancer Survivor Study (CCSS) indicated that at least $20 \%$ of childhood cancer survivors, including $15 \%$ of those with a previous leukemia diagnosis, reported problems with physical performance as young adults [8]. The selfreported design of this large epidemiologic study did not allow direct measurement of impairments underlying functional losses. Physical fitness deficits in adult survivors of childhood acute lymphoblastic leukemia (ALL) have been documented [9], and are attributed either to a lack of physical activity [10], or, in individuals who received high doses of anthracyclines, to underlying cardiostructural problems [11-13]. Although fitness deficits are reported to be associated with adiposity, defined as percent body fat, it is not clear whether the changes in body composition leads to reduced fitness or whether the reduced fitness leads to changes in body composition, or both [14].

Body composition imbalances, defined, for instance, as having more fat and less lean body mass, have the potential to reduce muscular strength, and decreased strength may impair the ability to participate in physical activity and thus perpetuate fitness deficits. Although lower extremity weakness was reported in a small group of children $(\mathrm{N}=8)$ during treatment for ALL [15] and in a larger group $(\mathrm{N}=43)$ of adolescent and young adult survivors of childhood ALL [5], there is scant data in the literature about muscle strength in adult survivors of childhood ALL, or the impact of body composition and growth hormone $(\mathrm{GH})$ status on muscle performance. Based on the premise that muscle strength may be abnormal in long-term cancer survivors, the aims of these analyses were to: (1) ascertain body composition, strength, and functional mobility among adult survivors of childhood ALL, and to compare these values to population normative values; (2) evaluate the impact of cranial radiation treatment and GH deficiency on muscle strength in survivors; and (3) evaluate the impact of muscle strength on functional mobility in survivors.

\footnotetext{
${ }^{1}$ Department of Pediatrics, Division of Epidemiology and Clinical Research, University of Minnesota, Minneapolis, Minnesota; ${ }^{2}$ Department of Pediatrics, Division of Hematology/Oncology/Blood and Marrow Transplantation, University of Minnesota Medical School, Minnesota; ${ }^{3}$ School of Kinesiology, University of Minnesota, Minneapolis, Minnesota; ${ }^{4}$ Department of Pediatrics, Division of Endocrinology, University of Minnesota, Minneapolis, Minnesota; ${ }^{5}$ Department of Pediatrics, Child Health Evaluation and Research (CHEAR) Unit, University of Michigan Medical School, Ann Arbor, Michigan
}

Presented in part at the 2006 American Society of Preventive Oncology (ASPO) Annual Meeting.

Grant sponsor: NIH Research Funding Support; Grant numbers: CA106778, M01-RR00400, CA55727, CA85503.

*Correspondence to: Kirsten K. Ness, Department of Pediatrics, Division of Epidemiology and Clinical Research, University of Minnesota, Mayo Mail Code 715, 420 Delaware Street S.E., Minneapolis, MN 55455. E-mail: ness@epi.umn.edu

Received 31 May 2006; Accepted 28 September 2006 


\section{METHODS}

\section{Sampling and Recruitment}

Eligible subjects were those diagnosed with ALL between 1970 and 1986 at age 20 years or younger who participated in the CCSS [16] and were treated at the University of Minnesota or Children's Hospitals and Clinical of Minneapolis and St. Paul. Details on the study design and methods of CCSS are provided elsewhere [16]. The evaluations reported here were included in a clinical study evaluating long-term effects of childhood ALL treatment, including the metabolic syndrome and GH deficiency [17]. In order to detect differences of at least $10 \%$ between our survivor group and population expected values, we recruited 75 participants from 213 potentially eligible individuals, 25 in each of 3 cranial radiation treatment groups (none, $<24 \mathrm{~Gy}, \geq 24 \mathrm{~Gy}$ ). Six cases $(2.8 \%$ ) were no longer eligible. Of the remaining 207, 29 (14\%) actively or passively refused participation, 22 were lost to follow-up (10.6\%), 10 agreed to participate $(4.8 \%)$ but were not scheduled because recruitment goals were met, and 71 (34.3\%) were never contacted because their random number was not reached in our recruitment protocol. The protocol was approved by the Human Subjects Review Committees (IRB) at both the University of Minnesota and Children's Hospitals and Clinics of Minneapolis/St. Paul.

\section{Measures}

The primary outcomes of interest for this analysis were body composition and functional mobility. Cranial radiation treatment and $\mathrm{GH}$ deficiency were considered as risk factors for the strength outcomes. Chemotherapy agents were evaluated and oxygen consumption was estimated [18], so that we could account for them in models that evaluated the associations between cranial radiation treatment with strength and functional mobility.

Anthropometrics. Height in centimeters and weight in kilograms were measured with a wall-mounted stadiometer, and on an electronic scale (Model 5002, Scale-Tronix, Inc., Wheaton, IL). Body mass index (BMI) was calculated by dividing weight in kilograms by height in meters squared.

Body composition. Percent body fat, lean body mass, skeletal muscle mass, and bone mineral content were determined by having participants undergo dual X-ray absorbtiometry (DEXA) scans. (Prodigy, 3M, Madison, WI; software version 6.7). Body regions were isolated from each other using DEXA regional computer generated default lines, with manual adjustment as described by Kim et al. [19]. Reference data described by McDowell et al. [20], Gallagher et al. [21,22], and Janssen et al. [23] were used as age and gender-specific population normative values.

Muscle strength. Knee extension strength, the maximal voluntary force participants could exert during a single contraction, was measured with a break test. A single tester used a Chattilion hand held myometer (model CSD 200, Ametek, Inc., Largo, FL). Participants were seated in a firm chair with the back and thighs fully supported, the pelvis and distal femurs secured. Resistance was applied just proximal to the malleoli [24]. Intraclass correlation coefficients (ICCs) from 0.90 to 0.99 are reported for this device using this technique, within and between sessions [26-32]. Hand grip strength in kilograms was measured using a Jamar hand grip dynamometer (Sammons Preston Rolyan, Nottinghamshire, UK). Participants were seated with the shoulder at $0-10$ degrees, the elbow flexed to 90 degrees, and the forearm in neutral [33]. ICCs for this hand grip device range from 0.85 to 0.98 [34,35]. Each participant completed three trials with each extremity for both knee extension and hand grip. Averages were used for analysis [25].

Oxygen consumption. Peak $\mathrm{VO}_{2}$, the volume of oxygen consumed per minute relative to body mass was estimated with the Duke Activity Status Index (DASI) [18]. This 12 item questionnaire is correlated with peak oxygen uptake (recorded via expired gas analysis) during graded exercise testing $(\mathrm{r}=0.81)$ [18]. The DASI has been compared to and validated with exercise testing in both healthy and sick populations [36-43]. It's value as a prognostic tool for myocardial ischemia and angiographically defined coronary disease has recently been reported [44]. Test scores were converted to $\mathrm{VO}_{2}$ max values where $\mathrm{VO}_{2}=0.43 \times$ $\mathrm{DASI}+9.6$.

Functional mobility. Mobility was evaluated by having each subject perform the "Timed Up and Go" (TUG) measure [45], the time in seconds it takes to stand up from a $46 \mathrm{~cm}$ height arm chair, walk a distance of $3 \mathrm{~m}$, turn, walk back to the chair and sit down. Each subject performed both a practice and a timed trial. Participants also completed the modified Cooper test where they walked in a corridor as fast as possible for 2 min. Distance was recorded in meters [46].

Growth hormone stimulation test. GH function was evaluated for 72 of the 75 participants with the GH-releasing hormone/ arginine stimulation test (GHRH/ARG) as described by Biller et al. [47] $\mathrm{GH}$ levels were obtained at 30, 40, 60, 90, and $120 \mathrm{~min}$ following a $1.0 \mu \mathrm{g} / \mathrm{kg}$ intravenous bolus administration of GHRH and a $0.5 \mathrm{~g} / \mathrm{kg}$ intravenous infusion of arginine [48]. Consistent with prior studies, participants with peak GH levels less than $9.0 \mu \mathrm{g} / \mathrm{L}$ were classified as $\mathrm{GH}$ deficient $[48,49]$.

Treatment data. Cranial radiation exposure and chemotherapy treatment data were obtained from the CCSS database. These data were previously abstracted from medical records for each CCSS participant by trained personnel [17].

\section{Data Analysis}

Descriptive statistics were calculated for demographic and treatment variables and compared between participants and eligible non-participants with two sample $t$-tests or Chi-squared tests. Mean values for body composition, strength, and mobility outcomes were calculated using sampling weights to account for our block randomization sampling scheme, and compared to age, gender, height, and weight-specific population normative values with paired $t$-tests. Pearson correlation coefficients were calculated to evaluate the association between body composition variables and strength and mobility outcomes. Based on previous research that demonstrated improved model fitting with non-linear strength variables [50-53], leg strength was dichotomized to those in the lower 10th percentile $(-1.3$ standard deviations or more below the population mean) versus higher than the 10th percentile, for use in regression analyses. The 10th percentile corresponds to a ratio of strength to body weight of $3.3 \mathrm{~N} / \mathrm{kg}$. Individuals with strength to body weight ratios between 3.0 and $3.5 \mathrm{~N} / \mathrm{kg}$ are at risk for impaired function [54]. Multiple variable linear regression models were used to evaluate the associations between cranial radiation treatment and continuous outcomes of strength, GH deficiency and strength, strength and distance walked in 2 min, and strength and seconds required to perform the TUG. Cranial radiation was first classified as 
none, $<24$ Gy and 24+ Gy; however, there were no significant differences in outcomes between the two groups who received radiation, so the two groups who received radiation were combined for the final models. All models were adjusted for age and gender. The evaluations of the impact of knee extension strength on the 2-min walk and the TUG were adjusted for peak oxygen consumption. Chemotherapy agents and total anthracycline doses were evaluated in the predictive models, however they were not found to be independent predictors of the outcome or confounders of the tested associations, so were not included in the final models. Stata version 8.1 was used for all analyses.

\section{RESULTS}

\section{Participants}

The characteristics of the participants and eligible nonparticipants are shown in Table I. Participants did not differ statistically from non-participants by age, gender, or chemotherapy agents received. Study participants were $41.3 \%$ male, had a mean age at interview of 30.2 years (standard deviation (SD) 7.1), a mean age at diagnosis of 5.6 years (SD 4.3), and had survived on average 24.6 years (SD 4.8). Participants differed from non-participants by cranial radiation dose by sampling design.

TABLE I. Demographic and Treatment Variables Between Study Participants and Eligible Non-Participants

\begin{tabular}{|c|c|c|c|}
\hline & Participants & Non-participants & \\
\hline & $\mathrm{N}=75$ & $\mathrm{~N}=132$ & \\
\hline & $\mathrm{N}(\%)$ & $\mathrm{N}(\%)$ & $P$-value \\
\hline \multicolumn{4}{|l|}{ Sex } \\
\hline Male & $31(41.3)$ & $64(48.5)$ & \multirow[t]{2}{*}{0.42} \\
\hline Female & $44(58.7)$ & $68(51.5)$ & \\
\hline \multicolumn{4}{|l|}{ Age group at interview } \\
\hline $19-29$ years & $40(53.3)$ & $61(46.2)$ & \multirow[t]{3}{*}{0.19} \\
\hline $30-39$ years & $27(36.0)$ & $63(47.7)$ & \\
\hline $40-45$ years & $8(10.7)$ & $8(6.1)$ & \\
\hline Mean age at interview (SD) in years & $30.2(7.1)$ & $30.9(6.3)$ & 0.50 \\
\hline Mean age at diagnosis (SD) in years & $5.6(4.3)$ & $5.4(4.0)$ & 0.72 \\
\hline Mean years of survival (SD) in years & $24.6(4.8)$ & $25.5(4.6)$ & 0.20 \\
\hline Body mass index-1995-1996 survey: mean (SD) & $23.6(5.9)$ & $24.5(4.6)$ & 0.28 \\
\hline \multicolumn{4}{|l|}{ Race } \\
\hline White & $74(98.7)$ & $127(96.2)$ & \multirow[t]{2}{*}{0.98} \\
\hline Non-white & $1(1.3)$ & $5(3.8)$ & \\
\hline \multicolumn{4}{|l|}{ Cranial radiation treatment group } \\
\hline None & $25(33.3)$ & $17(12.9)$ & \multirow[t]{3}{*}{0.001} \\
\hline$<24 \mathrm{~Gy}$ & $25(33.3)$ & $70(53.0)$ & \\
\hline $24+\mathrm{Gy}$ & $25(33.3)$ & $45(34.1)$ & \\
\hline \multicolumn{4}{|l|}{ Body areas in radiation fields } \\
\hline Brain & $50(66.7)$ & $115(87.1)$ & $<0.001$ \\
\hline Spine & $17(22.7)$ & $27(20.5)$ & 0.71 \\
\hline Total body & $5(6.7)$ & $4(3.0)$ & 0.22 \\
\hline \multicolumn{4}{|l|}{ Chemotherapy agents received } \\
\hline Actinomycin & $1(1.3)$ & $0(0.0)$ & 0.18 \\
\hline Cytoxan & $33(44.0)$ & $64(48.5)$ & 0.53 \\
\hline Ara-C & $33(44.0)$ & $58(43.9)$ & 0.99 \\
\hline Daunorubicin & $21(28.0)$ & $30(22.7)$ & 0.39 \\
\hline Dexamethasone & $11(14.7)$ & $20(15.2)$ & 0.92 \\
\hline Doxorubicin & $21(28.0)$ & $51(38.6)$ & 0.12 \\
\hline Isofosfomide & $1(1.3)$ & $1(0.8)$ & 0.68 \\
\hline L-aspariginase & $72(96.0)$ & $122(92.4)$ & 0.31 \\
\hline 6-Mercaptopurine & $69(92.0)$ & $119(90.2)$ & 0.66 \\
\hline Methotrexate & $75(100.0)$ & $132(100.0)$ & 0.99 \\
\hline Prednisone & $74(98.7)$ & $129(97.7)$ & 0.64 \\
\hline 6-Thioguanine & $18(24.0)$ & $29(22.0)$ & 0.74 \\
\hline Vincristine & $75(100.0)$ & $131(99.2)$ & 0.45 \\
\hline VM-26 & $2(2.7)$ & $1(0.8)$ & 0.27 \\
\hline Allopurinol & $2(2.7)$ & $1(0.8)$ & 0.27 \\
\hline \multicolumn{4}{|l|}{ Anthracycline dose } \\
\hline None & $46(61.3)$ & $77(58.3)$ & \multirow[t]{4}{*}{0.07} \\
\hline $1-100 \mathrm{mg} / \mathrm{m}^{2}$ & $10(13.3)$ & $6(4.5)$ & \\
\hline $101-300 \mathrm{mg} / \mathrm{m}^{2}$ & $11(14.7)$ & $31(23.5)$ & \\
\hline $301+\mathrm{mg} / \mathrm{m}^{2}$ & $8(10.7)$ & $18(13.6)$ & \\
\hline
\end{tabular}




\section{Body Composition}

Observed and expected means of body composition, strength, and mobility values for the ALL survivors are shown in Table II. BMI and bone mineral content did not differ between study participants and expected population normative values, however percent fat mass was higher and percent skeletal and lean body mass were lower in study participants when compared to population normative values. Mean BMI among study participants was $26.8 \mathrm{~kg} /$ $\mathrm{m}^{2}$ for males and $27.9 \mathrm{~kg} / \mathrm{m}^{2}$ for females, compared to expected mean values [20] of $27.5 \mathrm{~kg} / \mathrm{m}^{2}(P=0.45)$ and $26.8 \mathrm{~kg} / \mathrm{m}^{2}$ $(P=0.37)$, respectively. Fat mass among males was $5.5 \%$, and among females was $2.0 \%$, higher than expected from population norms. Lean body mass was $4.7 \%(P=0.001)$ lower among males and $2.2 \%(P=0.13)$ lower among females, and skeletal lean body mass was $2.5 \%(P=0.007)$ lower among males and $2.2 \%$ $(P=0.007)$ lower among females than expected when compared to population normative values [21-23].

\section{Strength}

Hand grip strength among our study participants was slightly, but not significantly lower than population normative values [33]. Knee extension strength was significantly lower among both male and female survivors of childhood ALL when compared to population normative values. On average, males had knee extension strength values slightly more than one standard deviation below, and females had knee extension strength nearly one standard deviation below the expected population mean [24]. Quadriceps strength was positively correlated with percent skeletal muscle mass $(\mathrm{r}=0.27, P=0.02)$, but not with BMI, percent lean body mass, or percent fat mass.

\section{Cardio-Pulmonary Fitness}

Self reported cardio-pulmonary fitness levels in the study population were also significantly lower than would be expected for same age and gender members of the normative population.
Based on participants' answers to the 12 questions on the DASI, males in our study had estimated mean peak $\mathrm{VO}_{2}$ levels $8.60 \mathrm{mg} / \mathrm{kg} /$ $\min (P<0.001)$ and females had estimated mean peak $\mathrm{VO}_{2}$ levels $4.62 \mathrm{mg} / \mathrm{kg} / \mathrm{min}(P<0.001)$ lower than predicted for their age and gender [55]. Peak $\mathrm{VO}_{2}$ was positively correlated with percent lean body mass $(\mathrm{r}=0.26, P=0.03)$ and percent skeletal muscle mass ( $\mathrm{r}=0.24, P=0.04)$, and negatively correlated with percent fat mass $(\mathrm{r}=-0.26, P=0.02)$ and BMI $(\mathrm{r}=-0.23, P=0.04)$.

\section{Mobility}

The time it took for participants to complete the TUG was $3.0 \mathrm{sec}$ $(P<0.001)$ longer for males and $2.9 \mathrm{sec}(P<0.001)$ longer for females than expected for same age, same gender, same height members of the normal population $[45,56,57]$. Study participants also walked significantly shorter distances in 2 min than expected for their same height, age, and gender members of the normal population (Table II) $[46,56-58]$. Time to complete the TUG was positively correlated with BMI $(\mathrm{r}=0.34, P=0.003)$.

\section{Strength and Mobility}

The association between knee extension strength and the mobility outcomes are shown in Figure 1A,B. After adjusting for age and peak $\mathrm{VO}_{2}$, study participants whose knee extension strength was at or less than -1.3 standard deviation below the population expected mean took slightly, but not significantly longer to perform the TUG and showed a trend toward walking shorter distances in 2 min when compared to those with knee extension strength greater than -1.3 standard deviations below the population mean.

\section{Cranial Radiation Treatment, Growth Hormone Deficiency, and Knee Extension Strength}

The impact of cranial radiation treatment on subsequent muscular strength is shown in Figure 2A. Both males and females

TABLE II. Mean Comparisons Body Composition, Strength, Mobility Study Participants, and Population Normative Values

\begin{tabular}{|c|c|c|c|c|c|c|c|c|c|c|}
\hline & \multicolumn{4}{|c|}{ Males } & \multirow[b]{3}{*}{$P$-value } & \multicolumn{4}{|c|}{ Females } & \multirow[b]{3}{*}{$P$-value } \\
\hline & \multicolumn{2}{|c|}{ Cases } & \multicolumn{2}{|c|}{$\begin{array}{l}\text { Normative } \\
\text { values }\end{array}$} & & \multicolumn{2}{|c|}{ Cases } & \multicolumn{2}{|c|}{$\begin{array}{l}\text { Normative } \\
\text { values }\end{array}$} & \\
\hline & Mean & SD & Mean & $\mathrm{SD}$ & & Mean & SD & Mean & $\mathrm{SD}$ & \\
\hline \multicolumn{11}{|l|}{ Body composition } \\
\hline BMI (kg/meter squared) & 26.8 & 5.3 & 27.5 & 0.3 & 0.45 & 27.9 & 8.1 & 26.8 & 0.3 & 0.37 \\
\hline Bone mineral content $\%$ & 4.0 & 0.6 & 3.8 & 0.5 & 0.16 & 3.6 & 0.6 & 3.8 & 0.5 & 0.15 \\
\hline Lean mass $\%$ & 70.0 & 7.7 & 74.7 & 8.4 & 0.001 & 58.0 & 10.0 & 60.2 & 5.3 & 0.13 \\
\hline Fat mass $\%$ & 26.0 & 8.0 & 21.5 & 7.6 & $<0.001$ & 38.0 & 9.6 & 36.0 & 9.7 & 0.001 \\
\hline Skeletal muscle mass $\%$ & 38.1 & 4.1 & 40.7 & 4.7 & 0.007 & 30.1 & 5.0 & 32.3 & 5.7 & 0.007 \\
\hline \multicolumn{11}{|l|}{ Strength } \\
\hline Left knee extension (Newtons) & 490.25 & 122.98 & 569.87 & 60.17 & 0.001 & 405.39 & 122.18 & 464.67 & 75.04 & 0.01 \\
\hline Right knee extension (Newtons) & 494.45 & 118.34 & 567.97 & 62.06 & 0.002 & 414.20 & 113.14 & 472.15 & 72.38 & 0.01 \\
\hline Left hand grip $(\mathrm{kg})$ & 49.30 & 10.05 & 50.18 & 1.80 & 0.63 & 30.40 & 8.16 & 29.00 & 1.23 & 0.26 \\
\hline Right hand grip (kg) & 54.13 & 9.43 & 55.36 & 1.69 & 0.47 & 32.44 & 8.76 & 34.00 & 1.32 & 0.24 \\
\hline \multicolumn{11}{|l|}{ Cardiopulmonary fitness } \\
\hline Peak V02 (ml/kg/min) & 32.40 & 4.68 & 41.00 & 5.68 & $<0.001$ & 29.18 & 7.12 & 33.80 & 4.89 & $<0.001$ \\
\hline \multicolumn{11}{|l|}{ Mobility } \\
\hline Timed up and go (seconds) & 5.82 & 0.99 & 2.84 & 0.22 & $<0.001$ & 5.88 & 1.32 & 3.00 & 0.28 & $<0.001$ \\
\hline Modified Cooper/2 min walk (meters) & 203.35 & 25.72 & 304.23 & 8.13 & $<0.001$ & 190.88 & 29.59 & 276.26 & 9.46 & $<0.001$ \\
\hline
\end{tabular}


A

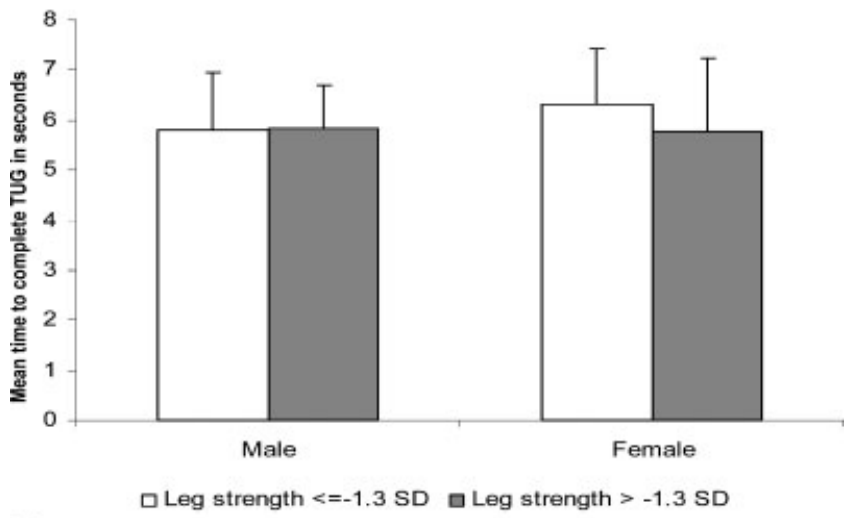

B

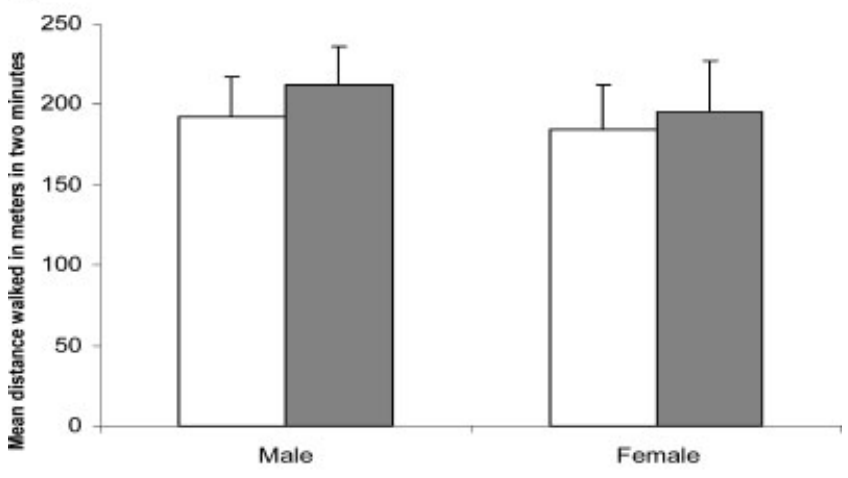

$\square$ Leg strength <=-1.3 SD $\square$ Leg strength > -1.3 SD

Fig. 1. Means and standard deviations, adjusted for age and $\mathrm{VO}_{2}$ max, for mobility tests show that females with decreased knee extension strength take longer to complete the timed up and go (TUG) (A) and that both males and females with decreased knee extension strength walk a shorter distance in the 2-min corridor walk (B) than those with knee extension strength -1.3 standard deviation or closer to the population mean. A: Male ranges: $4.08-7.82 \mathrm{sec}$ (leg strength $<=-1.3$ SD) versus $4.51-8.03 \mathrm{sec}$ (leg strength $>-1.3 \mathrm{SD}$ ), $P=0.47$. Female ranges: 4.58 $8.10 \mathrm{sec}$ (leg strength $<=-1.3 \mathrm{SD}$ ) versus $3.82-11.11 \mathrm{sec}$ (leg strength $>-1.3 \mathrm{SD}$ ), $P=0.53$. B: Male ranges: $155.45-233.78 \mathrm{~m}$ (leg strength $<=1.3 \mathrm{SD}$ ) versus $165.58-266.38 \mathrm{~m}$ (leg strength $>1.3 \mathrm{SD}$ ), $P=0.10$. Female ranges: $134.72-242.01 \mathrm{~m}$ (leg strength $<=1.3 \mathrm{SD}$ ) versus 131.06-263.04 m (leg strength $>1.3 \mathrm{SD}$ ), $P=0.16$.

who received cranial radiation had lower strength than those who did not, however, the impact of the treatment is statistically significant only in females. In an age-adjusted model, females who received cranial radiation had mean knee extension strength values 58.15 Newtons lower than those who did not receive radiation. GH deficiency also was associated with impaired strength among females (Fig. 2B). Again, adjusting for age, females with peak GH levels $\leq 9.0 \mu \mathrm{g} / \mathrm{L}$ had an average knee extension strength value 69.14 Newtons less than those who had peak GH levels $>9.0 \mu \mathrm{g} / \mathrm{L}$ $(P=0.05)$. The correlation between radiation treatment group and peak GH levels was $-0.63(P<0.001)$.

\section{DISCUSSION}

Adult survivors of childhood ALL have lower lean body and skeletal muscle mass, weaker leg strength, and impaired mobility
A

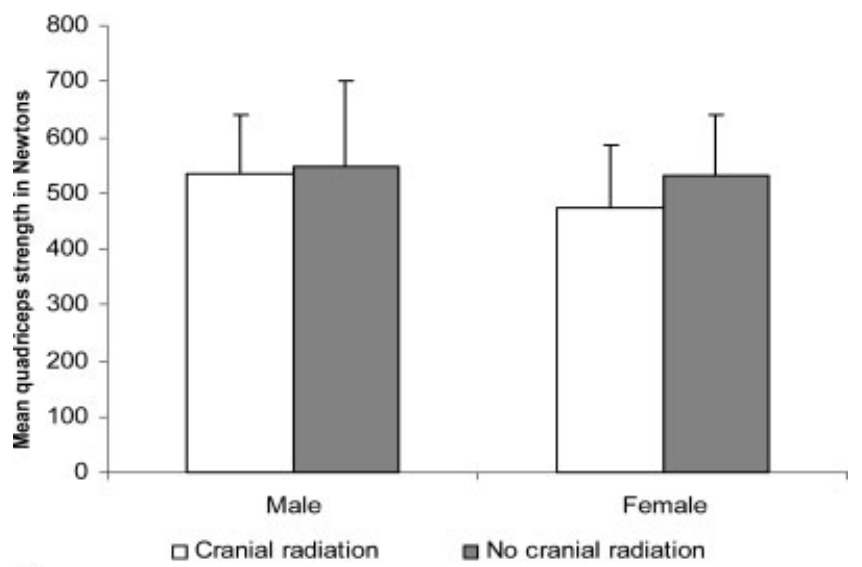

B

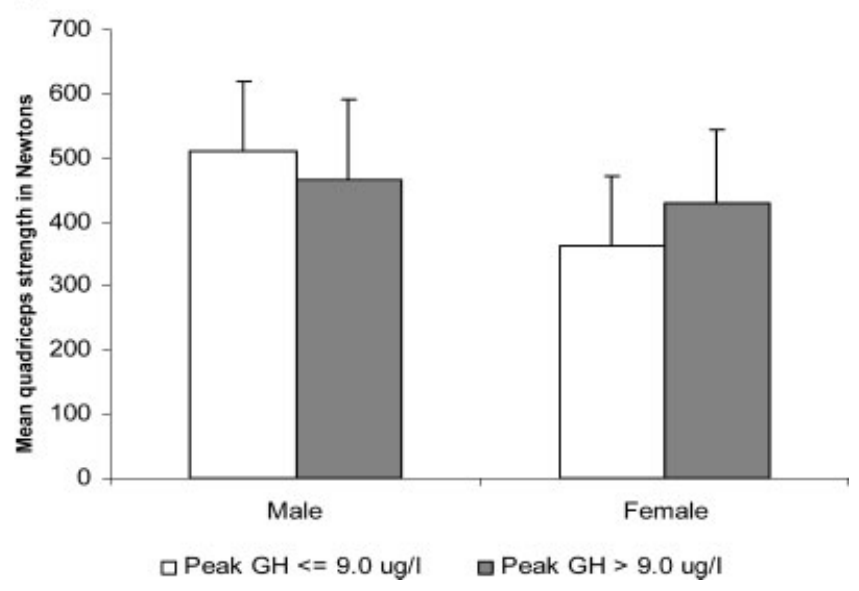

Fig. 2. Means and standard deviations for quadriceps strength from a multiple variable model adjusted for age show that a history of cranial radiation $(\mathbf{A})$ and growth hormone insufficiency $(\mathbf{B})$ are associated with decreased quadriceps strength among females. A: Male ranges: $243.23-$ 627.20 Newtons (cranial radiation) versus 214.67-665.47 Newtons (no cranial radiation), $P=0.75$. Female ranges: $185.73-607.60$ Newtons (cranial radiation) versus 274.40-697.20 Newtons (no cranial radiation), $P=0.05$. B: Male ranges: 289.33-665.47 Newtons (growth hormone deficiency) versus 214.67-622.52 Newtons (no growth hormone deficiency), $P=0.37$. Female ranges: $185.73-548.80$ Newtons (growth hormone deficiency) 215.60-697.20 Newtons (no growth hormone deficiency), $P=0.05$.

when compared to same sex, same age, same body weight population norms. Previous treatment with cranial radiation and current GH deficiency are associated with decreased strength in female ALL survivors. After adjusting for age and peak $\mathrm{VO}_{2}$, female ALL survivors with leg strength in the lowest 10th percentile of population norms take longer to complete the TUG and walk fewer meters in 2 min than do ALL survivors who have knee extension strength above the population 10th percentile, although these values were not statistically significant in our sample.

Our findings regarding body composition, muscle strength, and cardio-respiratory fitness are consistent with other research $[5,14,59]$. We found increased fat mass values slightly higher than those reported by Warner et al. [14] in ALL survivors who were still children perhaps indicating that treatment-related changes in body 
composition continue well into adulthood. Lower extremity strength deficits in our study participants were not as severe as than those reported by Marchese et al. [15] in children undergoing treatment for ALL. Strength deficits in our female participants were also less marked than those reported by Hovi et al. in a younger (mean age $=19$ years) cohort of female ALL survivors, suggesting that either some recovery of strength occurs with distance from leukemia treatment or that members of the normal population also experience strength losses during early adult years. Both cranial radiation and GH deficiency were associated with strength deficits among the females in our study. These findings support previous reports of an association between cranial radiation and muscle weakness [5], and an association between GH deficiency and percent body fat in ALL survivors [59]. The deficit in peak oxygen consumption in our study cohort of childhood ALL survivors, as expected, was similar to the $-5.97 \mathrm{ml} / \mathrm{kg} / \mathrm{min}$ value reported in a systematic review of the literature reporting cardio-respiratory fitness among ALL survivors [9].

Although the body composition, strength, and cardio-respiratory findings we describe provide support to the small body of existing literature, the magnitudes of functional limitations in our study participants, and the potential association of functional limitations with lower extremity strength deficits, are novel findings. Strengthening interventions to improve muscle weakness may help ALL survivors overcome functional loss. The association between weakness and function during treatment has been reported previously among children [15]; our findings of similar losses in long-term adult survivors, however, indicate a potential need for intervention strategies even many years following treatment.

There are several limitations that should be taken into account when interpreting the results of this study. First, our sample size was largely limited to a Caucasian population reflective of the racial and ethnic make-up of Minneapolis and St. Paul between 1970 and 1986. We were unable to determine if body composition, strength, or mobility differed as a function of race or ethnicity. Although larger than other studies specific to muscle strength and function among ALL patients or survivors [5,15], our sample size of 75 is still relatively small and some associations may reflect random variability as a statistical explanation for the differences. Third, if muscle strength deficits are attributable to cranial irradiation and subsequent GH deficiency, our findings have less relevance to ALL survivors diagnosed in a more recent era because of the substantially reduced reliance on cranial radiation treatment in modern risk-based ALL therapy. Nevertheless, our findings are important to the thousands of ALL survivors who were treated with cranial irradiation in an earlier era and to those with T-cell phenotype, those with central nervous system disease at diagnosis, and those with relapsed ALL who are still treated with cranial radiation. They potentially are also important for children diagnosed with brain and spinal cord tumors who receive cranial radiation, and for children who received total body irradiation in preparation for hematopoietic stem cell transplantation. Lastly, because our study participants received very similar chemotherapeutic regimens, we were unable to evaluate the effects of neurotoxic agents, like vincristine, on muscle strength and function.

In summary, long-term adult survivers of childhood ALL in this study had significant lower extremity muscle weakness and also subtle limitations in mobility that may interfere with activities that require lower extremity power, sustained mobility and movement transitions. These limitations in strength and mobility may have a deleterious effect on functional capabilities, including participation in leisure and physical activity.

\section{REFERENCES}

1. Jagoe RT, Goldberg AL. What do we really know about the ubiquitin-proteasome pathway in muscle atrophy? Curr Opin Clin Nutr Metab Care 2001;4:183-190.

2. Schwartz AL, Ciechanover A. The ubiquitin-proteasome pathway and pathogenesis of human diseases. Annu Rev Med 1999;50: $57-74$.

3. Bodine SC, Latres E, Baumhueter S, et al. Identification of ubiquitin ligases required for skeletal muscle atrophy. Science 2001;294:1704-1708.

4. Li YP, Chen Y, Li AS, et al. Hydrogen peroxide stimulates ubiquitin-conjugating activity and expression of genes for specific e2 and e3 proteins in skeletal muscle myotubes. Am J Physiol Cell Physiol 2003;285:C806-C812.

5. Hovi L, Era P, Rautonen J, et al. Impaired muscle strength in female adolescents and young adults surviving leukemia in childhood. Cancer 1993;72:276-281.

6. Brill PA, Macera CA, Davis DR, et al. Muscular strength and physical function. Med Sci Sports Exerc 2000;32:412-416.

7. Frederiksen H, Gaist D, Petersen HC, et al. Hand grip strength: A phenotype suitable for identifying genetic variants affecting midand late-life physical functioning. Genet Epidemiol 2002;23:110122.

8. Ness KK, Mertens AC, Hudson MM, et al. Limitations on physical performance and daily activities among long-term survivors of childhood cancer. Ann Intern Med 2005;143:639-647.

9. van Brussel M, Takken T, Lucia A, et al. Is physical fitness decreased in survivors of childhood leukemia? A systematic review. Leukemia 2005;19:13-17.

10. Demark-Wahnefried W, Werner C, Clipp EC, et al. Survivors of childhood cancer and their guardians. Cancer 2005;103:2171-2180.

11. Jakacki RI, Goldwein JW, Larsen RL, et al. Cardiac dysfunction following spinal irradiation during childhood. J Clin Oncol 1993; 11:1033-1038.

12. Lipshultz SE, Colan SD, Gelber RD, et al. Late cardiac effects of doxorubicin therapy for acute lymphoblastic leukemia in childhood. N Engl J Med 1991;324:808-815.

13. Smibert E, Carlin JB, Vidmar S, et al. Exercise echocardiography reflects cumulative anthracycline exposure during childhood. Pediatr Blood Cancer 2004;42:556-562.

14. Warner JT, Bell W, Webb DK, et al. Relationship between cardiopulmonary response to exercise and adiposity in survivors of childhood malignancy. Arch Dis Child 1997;76:298-303.

15. Gocha Marchese V, Chiarello LA, Lange BJ. Strength and functional mobility in children with acute lymphoblastic leukemia. Med Pediatr Oncol 2003;40:230-232.

16. Robison LL, Mertens AC, Boice JD, et al. Study design and cohort characteristics of the childhood cancer survivor study: A multiinstitutional collaborative project. Med Pediatr Oncol 2002;38: 229-239.

17. Gurney JG, Ness KK, Sibley SD, et al. Metabolic syndrome and growth hormone deficiency in adult survivors of childhood acute lymphoblastic leukemia. Cancer 2006;107:1303-1312.

18. Hlatky MA, Boineau RE, Higginbotham MB, et al. A brief self-administered questionnaire to determine functional capacity (the duke activity status index). Am J Cardiol 1989;64:651-654.

19. Kim J, Wang Z, Heymsfield SB, et al. Total-body skeletal muscle mass: Estimation by a new dual-energy X-ray absorptiometry method. Am J Clin Nutr 2002;76:378-383.

20. McDowell MA, Fryar CD, Hirsch R, et al. Anthropometric reference data for children and adults: US Population, 19992002. Adv Data 2005:1-5. 
21. Gallagher D, Heymsfield SB, Heo M, et al. Healthy percentage body fat ranges: An approach for developing guidelines based on body mass index. Am J Clin Nutr 2000;72:694-701.

22. Gallagher D, Visser M, De Meersman RE, et al. Appendicular skeletal muscle mass: Effects of age, gender, and ethnicity. J Appl Physiol 1997;83:229-239.

23. Janssen I, Heymsfield SB, Wang ZM, et al. Skeletal muscle mass and distribution in 468 men and women aged 18-88 yr. J Appl Physiol 2000;89:81-88.

24. Bohannon RW. Reference values for extremity muscle strength obtained by hand-held dynamometry from adults aged 20 to 79 years. Arch Phys Med Rehabil 1997;78:26-32.

25. Gagnon D, Nadeau S, Gravel D, et al. Reliability and validity of static knee strength measurements obtained with a chair-fixed dynamometer in subjects with hip or knee arthroplasty. Arch Phys Med Rehabil 2005;86:1998-2008.

26. Bohannon RW. Hand-held compared with isokinetic dynamometry for measurement of static knee extension torque (parallel reliability of dynamometers). Clin Phys Physiol Meas 1990;11: 217-222.

27. Roy MA, Doherty TJ. Reliability of hand-held dynamometry in assessment of knee extensor strength after hip fracture. Am J Phys Med Rehabil 2004;83:813-818.

28. Wang CY, Olson SL, Protas EJ. Test-retest strength reliability: Hand-held dynamometry in community-dwelling elderly fallers. Arch Phys Med Rehabil 2002;83:811-815.

29. Roebroeck ME, Harlaar J, Lankhorst GJ. Reliability assessment of isometric knee extension measurements with a computer-assisted hand-held dynamometer. Arch Phys Med Rehabil 1998;79:442448.

30. Bohannon RW. Hand-held dynamometry: Factors influencing reliability and validity. Clin Rehabil 1997;11:263-264.

31. Bohannon RW. Test-retest reliability of hand-held dynamometry during a single session of strength assessment. Phys Ther 1986; 66:206-209.

32. de Boer A, Boukes RJ, Sterk JC. Reliability of dynamometry in patients with a neuromuscular disorder. Eng Med 1982;11:169-174.

33. Mathiowetz V, Kashman N, Volland G, et al. Grip and pinch strength: Normative data for adults. Arch Phys Med Rehabil 1985; 66:69-74.

34. Peolsson A, Hedlund R, Oberg B. Intra- and inter-tester reliability and reference values for hand strength. J Rehabil Med 2001;33: $36-41$.

35. Mathiowetz V, Weber K, Volland G, et al. Reliability and validity of grip and pinch strength evaluations. J Hand Surg [Am] 1984;9: 222-226.

36. Alonso J, Permanyer-Miralda G, Cascant P, et al. Measuring functional status of chronic coronary patients. Reliability, validity and responsiveness to clinical change of the reduced version of the duke activity status index (dasi). Eur Heart J 1997; 18:414-419.

37. Bairey Merz CN, Olson M, McGorray S, et al. Physical activity and functional capacity measurement in women: A report from the nhlbi-sponsored wise study. J Womens Health Gend Based Med 2000;9:769-777.

38. Carter R, Holiday DB, Grothues C, et al. Criterion validity of the duke activity status index for assessing functional capacity in patients with chronic obstructive pulmonary disease. J Cardiopulm Rehabil 2002;22:298-308.

39. Hamilton DM, Haennel RG. Validity and reliability of the 6-minute walk test in a cardiac rehabilitation population. J Cardiopulm Rehabil 2000;20:156-164.

40. McGlade DP, Poon AB, Davies MJ. The use of a questionnaire and simple exercise test in the preoperative assessment of vascular surgery patients. Anaesth Intensive Care 2001;29:520-526.
41. Nelson CL, Herndon JE, Mark DB, et al. Relation of clinical and angiographic factors to functional capacity as measured by the duke activity status index. Am J Cardiol 1991;68:973-975.

42. Nichol G, Llewellyn-Thomas HA, Thiel EC, et al. The relationship between cardiac functional capacity and patients' symptomspecific utilities for angina: Some findings and methodologic lessons. Med Decis Making 1996;16:78-85.

43. Von Dras DD, Siegler IC, Williams RB, et al. Surrogate assessment of coronary artery disease patients' functional capacity. Soc Sci Med 1997;44:1491-1502.

44. Shaw LJ, Olson MB, Kip K, et al. The value of estimated functional capacity in estimating outcome: Results from the nhbli-sponsored women's ischemia syndrome evaluation (wise) study. J Am Coll Cardiol 2006;47:S36-43.

45. Podsiadlo D, Richardson S. The timed "Up \& go": A test of basic functional mobility for frail elderly persons. J Am Geriatr Soc 1991;39:142-148.

46. Butland RJ, Pang J, Gross ER, et al. Two-, six-, and 12-minute walking tests in respiratory disease. Br Med J (Clin Res Ed) 1982; 284:1607-1608.

47. Biller BM, Samuels MH, Zagar A, et al. Sensitivity and specificity of six tests for the diagnosis of adult gh deficiency. J Clin Endocrinol Metab 2002;87:2067-2079.

48. Ghigo E, Aimaretti G, Arvat E, et al. Growth hormone-releasing hormone combined with arginine or growth hormone secretagogues for the diagnosis of growth hormone deficiency in adults. Endocrine 2001;15:29-38.

49. Link K, Moell C, Garwicz S, et al. Growth hormone deficiency predicts cardiovascular risk in young adults treated for acute lymphoblastic leukemia in childhood. J Clin Endocrinol Metab 2004;89:5003-5012.

50. Buchner DM, Cress ME, Esselman PC, et al. Factors associated with changes in gait speed in older adults. J Gerontol A Biol Sci Med Sci 1996;51:M297-302.

51. Buchner DM, Larson EB, Wagner EH, et al. Evidence for a nonlinear relationship between leg strength and gait speed. Age Ageing 1996;25:386-391.

52. Ferrucci L, Guralnik JM, Buchner D, et al. Departures from linearity in the relationship between measures of muscular strength and physical performance of the lower extremities: The women's health and aging study. J Gerontol A Biol Sci Med Sci 1997;52: M275-285.

53. Rantanen T, Parkatti T, Heikkinen E. Muscle strength according to level of physical exercise and educational background in middleaged women in finland. Eur J Appl Physiol Occup Physiol 1992; 65:507-512.

54. Ploutz-Snyder LL, Manini T, Ploutz-Snyder RJ, et al. Functionally relevant thresholds of quadriceps femoris strength. J Gerontol A Biol Sci Med Sci 2002;57:B144-152.

55. Franklin BA, Whaley MH, Howley ET, et al. Acsm's guidelines for exercise testing and prescription. Philadelphia: Lippincott, Williams \& Wilkins; 2000. 77

56. Samson MM, Meeuwsen IB, Crowe A, et al. Relationships between physical performance measures, age, height and body weight in healthy adults. Age Ageing 2000;29:235-242.

57. Steffen TM, Hacker TA, Mollinger L. Age- and gender-related test performance in community-dwelling elderly people: Six-minute walk test, berg balance scale, timed up \& go test, and gait speeds. Phys Ther 2002;82:128-137.

58. Gibbons WJ, Fruchter N, Sloan S, et al. Reference values for a multiple repetition 6-minute walk test in healthy adults older than 20 years. J Cardiopulm Rehabil 2001;21:87-93.

59. Jarfelt M, Lannering B, Bosaeus I, et al. Body composition in young adult survivors of childhood acute lymphoblastic leukaemia. Eur J Endocrinol 2005;153:81-89. 